\title{
Knowledge and practices of dentists regarding MERS-CoV
}

\author{
A cross-sectional survey in Saudi Arabia
}

Balgis O. Gaffar, MSc, JMHPE, Maha El Tantawi, MSc, PhD, Asim A. Al-Ansari, MDSc, DScD, Adel S. AlAgl, DSc, ABP, Faraz A. Farooqi, MSc, MBA, Khalid M. Almas, FDSRCS, FRACDS.

\begin{abstract}
الأهداف : تقييم معرفة أطباء الأسنان لفيروس الكورونا في المملكة

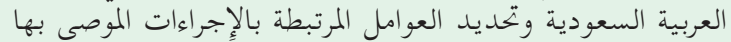
للتعامل مع مرضى الكورونا.

الطريقة: تم توزيع استبيان مصمهم لغرض الدراسة على أطباء

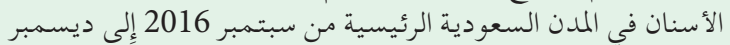

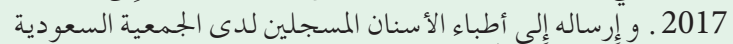

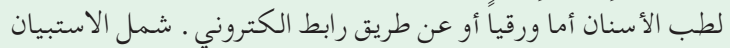

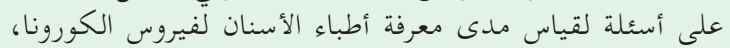

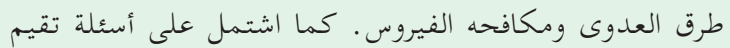

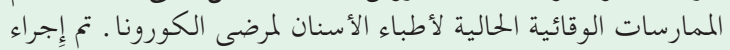

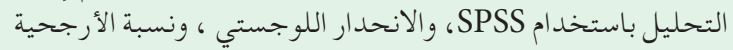

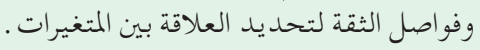

النتائج : تم تعبئة الاستبيان من قبل 423 طبيب أسنان . كانت المعرفة

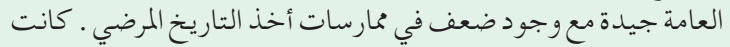

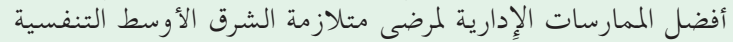

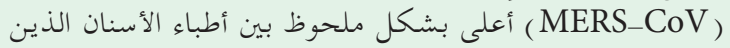

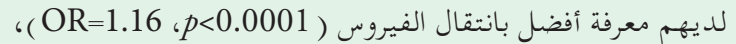

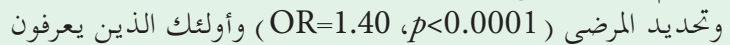

أن عدوى كورونا يمكن أن تكون قاتلة (OR= 2.44,p=0.02)

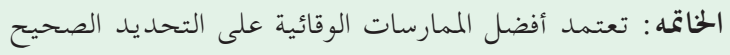

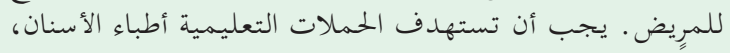

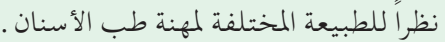

Objectives: To assess virus knowledge among dentists in Saudi Arabia and to identify factors associated with recommended management practices of patients.

Method: A structured questionnaire was distributed to dentists in major Saudi cities between September 2016 and December 2017. The questionnaire investigated participants' knowledge about Middle East
Respiratory Syndrome Coronavirus (MERS-CoV) transmission, consequences, patient identification and history taking practices. Data was collected using paper-based questionnaires or an online link sent to dentists registered with Saudi Dental Society nationwide. The analysis was carried using Statistical Package for Social Sciences for Windows, version 22.0 (IBM Corp., Armonk, NY, USA) logistic regression, odds ratio and confidence intervals to identify the relationship between variables.

Results: A total of 423 dentists responded the paperbased questionnaire. Overall the knowledge was good with gaps in history taking practices. Best management practices of MERS-CoV patients were significantly higher among dentists with better knowledge of virus transmission (odd ration $[\mathrm{OR}]=1.16, p<0.0001$ ), patients' identification $(\mathrm{OR}=1.40, p<0.0001)$ and those knowing that corona infection can be fatal $(\mathrm{OR}=2.44, p=0.02)$.

Conclusion: Best management practices depends on correct patient identification. Educational campaigns should target dentists, given the unique nature of dental practice.

Saudi Med J 2019; Vol. 40 (7): 714-720 doi: 10.15537/smj.2019.7.24304

From the Preventive Dental Sciences Department (Gaffar, El Tantawi, Al-Ansari, AlAgl, Almas), and from the Deanship of Academic Affairs (Farooqi), College of Dentistry, Imam Abdulrahman bin Faisal University, Dammam, Kingdom of Saudi Arabia.

Received 27th February 2019. Accepted 6th June 2019.

Address correspondence and reprint request to: Dr. Balgis O. Gaffar, Dental Sciences Department, College of Dentistry, Imam Abdulrahman bin Faisal University, Dammam, Kingdom of Saudi Arabia.

E-mail: bgosman@iau.edu.sa

ORCID ID: https://orcid.org/0000-0001-7593-1887 
$\mathrm{T}$ he Middle East Respiratory Syndrome Coronavirus (MERS-CoV) infection is a respiratory disease caused by a virus belonging to the genus betacoronavirus. ${ }^{1}$ The virus is linked to the Middle East with the highest number of cases reported in Saudi Arabia. ${ }^{2}$ The intensity of the infection ranges from mild flu-like symptoms to acute fatal condition. ${ }^{3}$ As with all respiratory infections, transmission is through close contact with infected persons by airborne or droplet inhalation. ${ }^{1-4}$ Bats and dromedary camels are the zoonotic origin of MERS-CoV and both are thought to be the source of primary infection with greater association reported in the case of camels. ${ }^{4}$ Secondary transmission occurs in health care settings ${ }^{5}$ including transmission between patients and healthcare providers., ${ }^{5,6}$

Since MERS-CoV was first discovered in 2012, Saudi Arabia has remained the country with the highest incidence and mortality rates ${ }^{7}$ with healthcare settings transmission reported. For example, one health care provider who used to work in Saudi Arabia and 185 Koreans who were linked to healthcare facilities in Saudi Arabia, Qatar, United Arab Emirates, and Bahrain were reported as infected. ${ }^{8}$ Another case was reported in Thailand for an Omani national who travelled to Bangkok for medical treatment. ${ }^{8}$ In 2015, a World Health Organization (WHO) report indicated that from 44 exported cases, only 6 acquired infection from non-human sources and 18 acquired infection within healthcare facilities. ${ }^{8}$

Patients attending dental facilities are potentially at great risk of MERS-CoV transmission due to close contact with other patients and the inevitable presence of splash and splatter. ${ }^{9}$ Because there is neither definitive treatment nor vaccine, ${ }^{1-5}$ prevention and infection control practices are crucial for disease control and prevention. Dentists' knowledge of MERS-CoV infection, transmission and preventive measures are essential for proper infection control practices. It is important that dentists are aware of the disease incubation period and that elective treatment is delayed until the incubation period has passed to reduce the risk of transmission. ${ }^{9}$

Saudi Arabia is still suffering from outbreaks of MERS-CoV, and the battle to control the infection

Disclosure. Authors have no conflict of interests, and the work was not supported or funded by any drug company. continues especially within healthcare facilities. ${ }^{10}$ Previous studies assessed the knowledge and awareness of the disease among health professions students, dental students, and dentists in some Saudi Arabia cities. ${ }^{11-14}$ Updating the information on current MERS-CoV knowledge and infection control practices among dentists on a wider scale in the country is needed to identify existing gaps and set ideal measures to address training deficiencies. Therefore, the aims of this study were to assess MERS-CoV knowledge among dentists in Saudi Arabia and to identify factors associated with adopting the recommended management practice of patients with MERS-CoV.

Methods. A cross-sectional, questionnaire-based study was conducted over one year between September 2016 and December 2017. The study was approved by the Research Unit, College of Dentistry, Imam Abdulrahman Bin Faisal University, Dammam, Saudi Arabia according to principles of the Helsinki Declaration. The target group was dentists in the private and public sectors in Saudi Arabia, regardless of their specialities and who agree to participate. The required sample size was calculated to be 383 dentists based on the following assumptions: margin of error $=5 \%$, confidence level $=95 \%$, percentage of dentists with correct knowledge or practices to control the disease $=50 \% .^{12}$

Based on previous studies, ${ }^{11-14}$ a self-administered questionnaire was developed in English (Appendix) to assess the dentists' knowledge on MERS-CoV using information from the websites of the WHO, Centre for Disease Control (CDC), and Saudi Ministry of Health $(\mathrm{MOH})$ as the scientific basis for the questionnaire. The questionnaire had a short introduction describing the purpose of the study and assuring dentists that responses would be confidential. It was divided into 5 sections assessing: 1) personal profile: age, gender, nationality, speciality, nature of practice (private or governmental sectors) and whether the respondent received continuing education (CE) about managing Corona infection in addition to sources of information about the disease; 2) knowledge of disease transmission ( $n=9$ questions); 3) knowledge of how to identify patients with Corona infection ( $\mathrm{n}=5$ questions); 4) history taking practices relevant to Corona infection $(\mathrm{n}=3$ questions); and 5) management of patients with Corona infection where a respondent can select one or more of 4 options. The last statement assessed the respondent's knowledge of whether Corona infection might be fatal. The questionnaire was pilot tested on 15 dentists who were not included in the study. Two 
strategies were used for data collection: 1) direct contact with participants at their workplace in major Saudi cities where dentists are concentrated (Riyadh, Jeddah, Makkah, Dammam, and Khobar) and during the major dental event of the Saudi Dental Society (SDS) conferences. In this case, the paper-based questionnaire was used. 2) An online survey was sent to dentists registered in the mailing list of the SDS. Participants were asked if they have filled the questionnaire before, to avoid duplication. Uncompleted questionnaires were excluded from the analysis.

Correct answers in each section were defined and internal consistency was assessed using Cronbach alpha. Scores were created by counting correct responses: a) knowledge of the virus transmission, b) how to identify patients with infection, and c) history taking practices relevant to MERS-CoV. Univariate logistic regression models were developed to assess the association of the outcome variable (referring patient to a hospital for further investigation as a recommended management practice) with each of the 3 scores, receiving training to manage the disease and knowing that the infection can have a fatal outcome. A multiple logistic regression model was also developed to include all variables adjusting for the personal and professional background. Odds ratio (OR), confidence intervals (CI), and $p$-values were calculated. The significance level was set at $5 \%$. Statistical analysis was carried out using Statistical Package for Social Sciences for Windows, version 22.0 (IBM Corp., Armonk, NY., USA)

Results. One hundred fifty-four paper-based questionnaires were received out of 200 distributed (77\%) and 269 responses were collected online out of a total of $801(33.6 \%)$ with total responses $=423 / 1001$ (response rate $=42.3 \%$ ). Our results show that $46.1 \%$ of participants were younger than 30 years of age and $64.5 \%$ of them were males. Most of them were Saudi $(62.9 \%)$, general dentists $(65.9 \%)$, and working in the governmental sector (60.8\%). Only 20.4\% attended $\mathrm{CE}$ to manage Corona infection (Table 1). The greatest percentage of respondents reported that they obtained information about the disease from the media (48.5\%) or $\mathrm{MOH}$ training (45.2\%). In addition, $20.3 \%$ reported they obtained information from the community they lived in, $18.4 \%$ from college and $14.9 \%$ reported no source of information.

Participants' knowledge regarding MERS-CoV transmission. Figure 1 shows that $\geq 78 \%$ knew that Corona can be prevented by good hygiene practices, that it spreads through contact with infected persons, and that infected patients should be isolated. Only 38.9\%
Table 1 - Personal and professional background of dentists participating in the study $(\mathrm{N}=423)$.

\begin{tabular}{|c|c|}
\hline Factors & n (\%) \\
\hline \multicolumn{2}{|l|}{ Age } \\
\hline$<30$ years & $195(46.1)$ \\
\hline $30+$ years & $226(53.7)$ \\
\hline \multicolumn{2}{|l|}{ Gender } \\
\hline Male & $273(64.5)$ \\
\hline Female & $150(35.5)$ \\
\hline \multicolumn{2}{|l|}{ Nationality } \\
\hline Saudi & $266(62.9)$ \\
\hline Non-Saudi & $157(37.1)$ \\
\hline \multicolumn{2}{|l|}{ Speciality $^{*}$} \\
\hline Specialist & $141(34.1)$ \\
\hline Not specialist & $273(65.9)$ \\
\hline \multicolumn{2}{|l|}{ Nature of practice* } \\
\hline Private sector & $161(38.1)$ \\
\hline Governmental sector ( $\mathrm{MOH} \&$ University) & $257(60.8)$ \\
\hline \multicolumn{2}{|l|}{ Attended CE to manage Corona infection* } \\
\hline Yes & $86(20.4)$ \\
\hline No & $335(79.6)$ \\
\hline
\end{tabular}

knew that Corona is contagious. Cronbach alpha for the internal consistency of the 9 statements assessing the knowledge of MERS-CoV transmission=0.85 and the mean \pm SD score (out of 9$)=6.36 \pm 2.88$.

Participants' knowledge regarding identification of patients with MERS-CoV. Figure 2 shows that $73.9 \%$ knew that MERS-CoV symptoms are similar to influenza and $65.8 \%$ knew that people with chronic diseases are at increased risk for Corona. Only 33.6\% knew that polymerase chain reaction (PCR) can be used to diagnose MERS-CoV. Cronbach alpha for the 5 statements assessing knowledge of how to identify patients with Corona $=0.59$. The mean \pm SD score (out of 5) $=2.70 \pm 1.48$.

History taking practices among study participants. Figure 3 shows that $36.3 \%$ of the respondents asked during history taking regarding residence history, $15.6 \%$ asked regarding travel history, and $9.9 \%$ asked regarding the history of contact with animals. Cronbach alpha for the internal consistency of the 3 statements assessing the history taking practices relevant to Corona infection $=0.61$. The mean \pm SD score out of $3=0.62 \pm 0.86$. Of all the participants, $47.5 \%$ referred a patient they suspected to be infected with MERS-CoV to a hospital for further investigation; $16.7 \%$ rescheduled these patients until symptoms cleared, $12.5 \%$ provided treatment to these patients, and 3.1\% referred them to another colleague. Most dentists $(n=330,78.2 \%)$ knew that MERS-CoV infection can be fatal.

Factors associated with best management practices among study participants. Table 2 shows that in 
univariate analysis, the odds of referring a patient for further investigations were significantly higher for those dentists with better knowledge of the virus transmission $(\mathrm{OR}=1.16, p<0.0001)$, better knowledge of how to identify a patient with Corona infection $(\mathrm{OR}=1.40, p<0.0001)$ and those knowing that Corona infection can be fatal $(\mathrm{OR}=2.44, p=0.02)$. In the multiple models adjusting for confounders, only knowing how to identify patients infected with Corona was significantly associated with referring patients for further investigations. Dentists with better knowledge of how to identify patients had 26\% higher odds of referring these patients $(\mathrm{AOR}=1.26,95 \% \mathrm{CI}=1.03$, $1.55)$.

Discussion. Our study provides insight about MERS-CoV knowledge and management practices among dentists in major Saudi cities. Dentists had

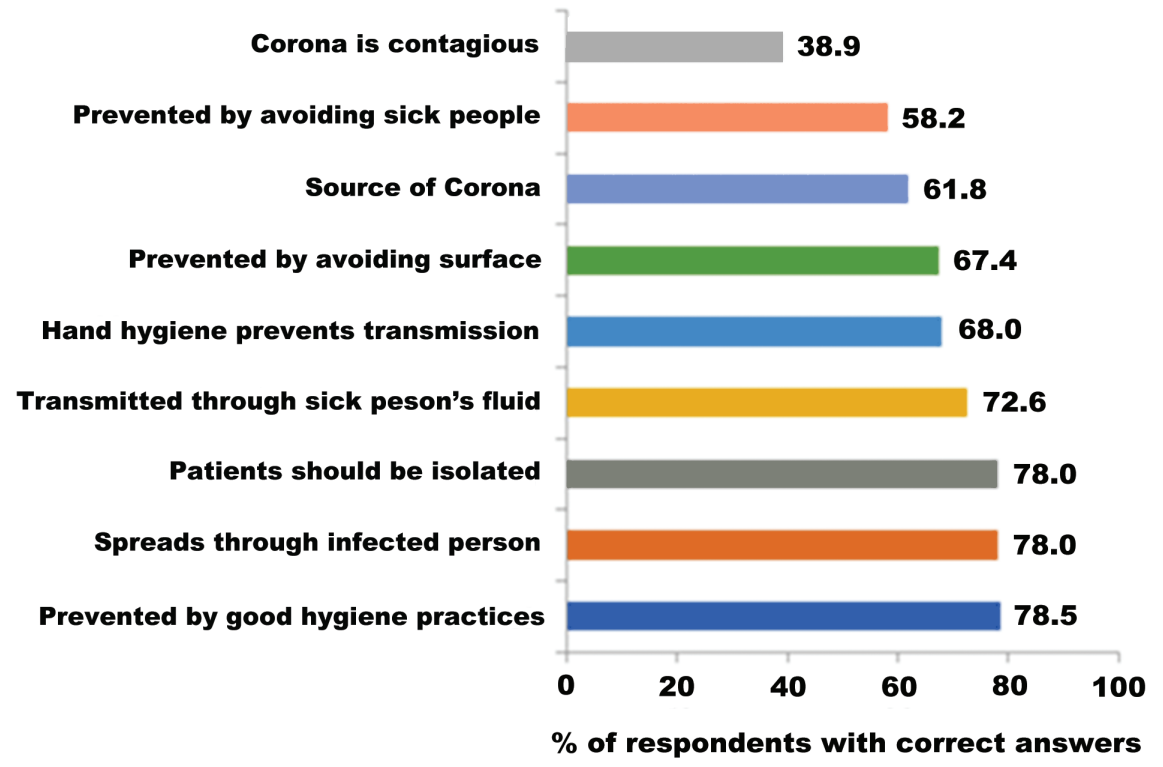

Figure 1 - Percentage of respondents with correct knowledge of MERS-CoV transmission.

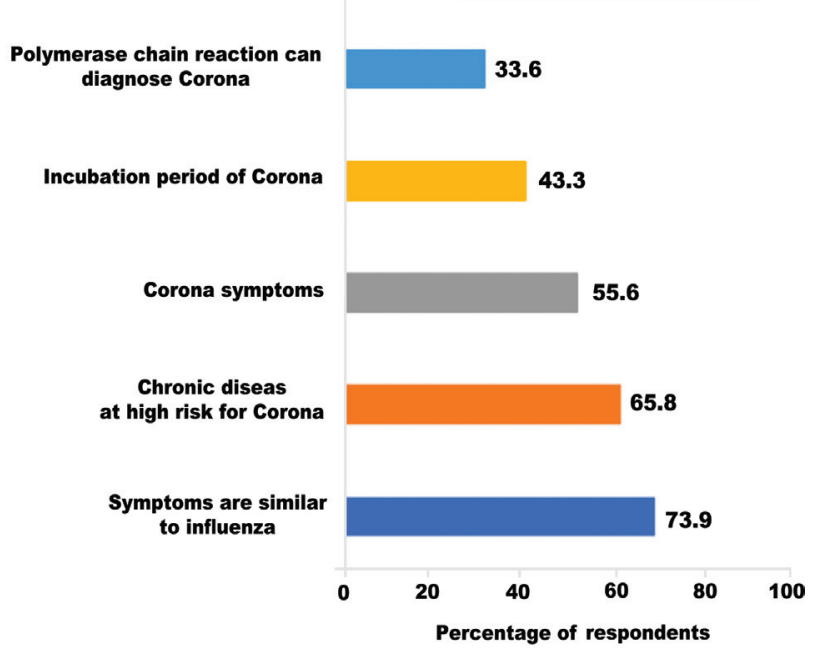

Figure 2 - Percentage of respondents with correct knowledge of how to identify patients with MERS-CoV infection.

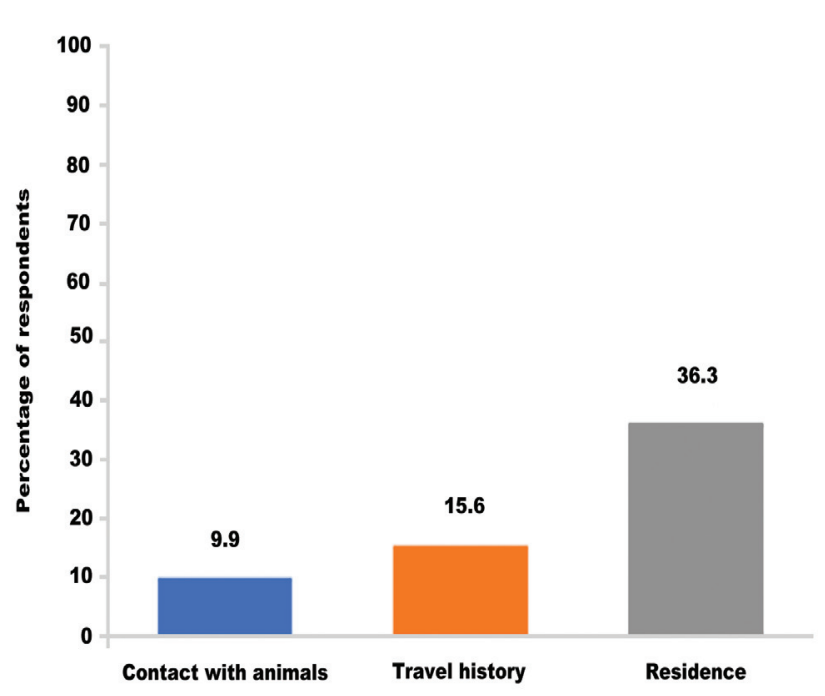

Figure 3 - Percentage of respondents with history taking practices relevant to MERS-CoV infection. 
Table 2 - Factors associated with referring patients for further investigations.

\begin{tabular}{|c|c|c|c|c|}
\hline Factors & UOR $(95 \% \mathrm{CI})$ & $P$-value & $\mathrm{AOR}(95 \% \mathrm{CI})$ & $P$-value \\
\hline Attended previous CE to manage MERS-CoV infection & $1.43(0.89,2.31)$ & 0.14 & $1.08(0.63,1.85)$ & 0.78 \\
\hline Knowledge of virus transmission & $1.16(1.08,1.25)$ & $<0.0001^{*}$ & $1.02(0.90,1.15)$ & 0.81 \\
\hline Knowledge of how to identify patients with MERS-CoV infection & $1.40(1.22,1.61)$ & $<0.0001^{*}$ & $1.26(1.03,1.55)$ & $0.03^{*}$ \\
\hline History taking practices relevant to MERS-CoV infection & $0.93(0.74,1.16)$ & 0.50 & $0.89(0.70,1.13)$ & 0.33 \\
\hline Knowing that MERS-CoV infection can be fatal & $2.44(1.14,5.21)$ & $0.02^{*}$ & $1.48(0.77,2.86)$ & 0.24 \\
\hline
\end{tabular}

good knowledge of MERS-CoV transmission, modest knowledge of how to identify infected patients and suboptimal history-taking practices relevant to the disease. Most participants referred suspected patients for further investigations, and this was associated with better knowledge of identifying infected patients.

Participants had a good knowledge of MERS-CoV transmission similar to dental professionals in Riyadh (10.61 \pm 1.19 , out of 11$)$ and contrary to healthcare providers in Makkah (18.3 \pm 3.9 , out of 28). ${ }^{11,14}$ Only $38.9 \%$ of the respondents in the present study knew that Corona is contagious which shows that there was an insufficient knowledge of the disease transmission. Previous studies showed that better knowledge about disease contagion was reported among healthcare providers ${ }^{14,15}$ than among dentists ${ }^{11,12,16}$ in spite of the close proximity of patient to provider that characterizes dental care. ${ }^{17}$

In the preent study, participants' knowledge of Corona infection was modest. This agrees with similar findings of previous Saudi Arabian studies where 54\% of dental students in Jeddah and $40.9 \%$ of healthcare providers in Makkah were able to identify disease symptoms; ${ }^{12,14}$ while better knowledge (84\%) was reported among health colleges' students in Najran. ${ }^{13}$ The difference between the previous findings and this study can be due to the increased awareness on the virus from $2015^{12,14}$ to $2017 .{ }^{13}$ The ability to identify persons infected with the disease is a ground stone in MERS-CoV infection prevention. ${ }^{4}$ Screening of patients by checking for clinical features associated with Corona such as fever, gastrointestinal, and respiratory symptoms may be instrumental in reducing the spread of MERS-CoV infection., ${ }^{4,8}$ Similarly, $<50 \%$ of respondents knew about the virus incubation period and methods to diagnose it. This is similar to the findings from previous studies conducted in Saudi Arabia where $30 \%$ of participants in Jeddah and $40.9 \%$ in Makkah knew about the incubation period. ${ }^{12,14}$ This knowledge is essential in determining the safe period to treat suspected patients. Only $33.6 \%$ of the participating dentists knew that PCR can be used to diagnose MERS-CoV. This was in agreement with Nour et $\mathrm{al}^{14}$ who reported that $40.9 \%$ of healthcare providers also lacked knowledge of appropriate diagnosis method for the disease. Laboratory tests can confirm the virus in respiratory tract secretions, faeces, serum and urine. ${ }^{10}$

In the present study, only $20.4 \%$ of the respondents attended CE on MERS-CoV. This disagrees with the emphasis on strict infection control guidelines by the national and international agencies to control MERS-CoV infection. ${ }^{4,8,9}$ The Saudi MOH campaigns in healthcare facilities during Corona outbreaks were reported to influence healthcare providers' practices. ${ }^{2,4}$ The decreased participation in CE may be attributed to some barriers such as technical difficulties (inability of some facilities to conduct such training sessions due to lack of place, equipment, inter-professional conflicts), heavy workload, lack of good role models, financial issues and unsupportive organizational culture. ${ }^{18}$ These reported barriers may explain the knowledge gaps identified in the current study and the suboptimal history-taking practices. The low level of attendance may also explain the lack of association with adopting recommended management practices which disagree with previous literature supporting the role of CE in healthcare workers' compliance with infection control guidelines. ${ }^{18}$ In the present study, 9.9\% assessed animal contact history although recent studies proved that camels ${ }^{19-21}$ and bats ${ }^{22.23}$ were reservoirs for MERS-CoV. Our findings agree with Nour et $\mathrm{al}^{14}$ who reported inadequate knowledge regarding the reservoir of infection among healthcare providers in Makkah as only $49.5 \%$ were aware of that.

In our study, only $15.6 \%$ of the participants assessed patients' travel history. Guidelines recommend evaluating the risk of MERS-CoV infection in symptomatic individuals returning from the Arabian Peninsula or high-risk cities within the past 14 days. ${ }^{24}$ Our findings disagree with a previous study reporting that $43.8 \%$ of healthcare providers in Makkah agreed with the importance of asking about travel history. ${ }^{14}$ The higher knowledge of travel history importance among healthcare providers can be justified by the 
awareness campaigns carried by $\mathrm{MOH}$ that usually target medical practitioners as compared to dental professionals. In addition, concerns about MERS-CoV focused on healthcare providers working in the central region of Saudi versus those working in other regions such as those included in our sample. ${ }^{16}$

Mass media (48.5\%) and $\mathrm{MOH}(45.2 \%)$ training were the main sources of participants knowledge. The role of Media as source of knowledge was also documented by Nour et $\mathrm{al}^{14}$ in Makkah (52.3\%), Abolfotouh et $\mathrm{al},{ }^{15}$ from various regions in Saudi Arabia (Eastern, Western, and Central) (76.2\%) as well as Almutairi ${ }^{16}$ who highlighted the role of media as a source of information. The role of Saudi $\mathrm{MOH}$ in providing information about the disease was minor in Jeddah (25\%). ${ }^{12}$ Although the role of mass media cannot be denied, it cannot be as reliable and professional as information provided by the $\mathrm{MOH}$.

Previous studies conducted among health and dental care providers in Saudi Arabia assessed knowledge, attitudes and current infection control practices. ${ }^{11-16}$ In the current study, we investigated participants' history taking and management practices, as emphasized by WHO. As these 2 are essential for controlling the disease. ${ }^{8,24}$

Our results showed that the ability to identify patients with the disease was associated with higher odds of adopting the recommended management practices. This agrees with a recent study which investigated the factors associated with dental students' management of patients with infectious disease and concluded that better-informed professionals show better management of patients. ${ }^{25}$

Our study had some limitations. First, the crosssectional nature of the study can only prove association and not a cause-effect relationship. Second, selfreporting should always be considered with caution since under or overestimation by the participants is likely to occur. Third, we were not able to study the impact of local workplace regulations on management practices among dentists and this may need to be assessed in future studies.

In conclusion, our study showed that dentists from major Saudi cities had a modest knowledge of MERS-CoV and insufficient history taking practices. Less than half of them adopted correct practices to manage patients suspected of Corona infection. These practices seem to be dependent mainly on identifying suspected patients through their signs and symptoms. As Saudi Arabia still suffers from outbreaks of Corona infection, continuous assessment of healthcare professional's knowledge and practices, especially among dentists, is crucial. On the other hand, evaluation of professional development programs by Ministry of Health is also needed to identify gaps and adopt best practices.

Acknowledgment. We acknowledge the efforts of Ms. Alaa Abdullah AlShaia, Ms. Shahad Alammar, and Dr. Zainab Alghareeb in the distribution and collection of the paper-based questionnaire. Also, we would like to thank SpringEdit Inc. (www. O1editor.info) for English language editing.

\section{References}

1. van Boheemen S, de Graaf M, Lauber C, Bestebroer TM, Raj VS, Zaki AM, et al. Genomic characterization of a newly discovered coronavirus associated with acute respiratory distress syndrome in humans. MBio 2012; 3: e00473-e00412.

2. Aleanizy FS, Mohmed N, Alqahtani FY, Mohamed RA. Outbreak of Middle East respiratory syndrome coronavirus in Saudi Arabia: a retrospective study. BMC Infect Dis 2017; 17: 23 .

3. Alsolamy S. Middle East respiratory syndrome: knowledge to date. Crit Care Med 2015; 43: 1283-1290.

4. Mohd HA, Al-Tawfiq JA, Memish ZA. Middle East respiratory syndrome coronavirus (MERS-CoV) origin and animal reservoir. Virol J 2016; 13: 87.

5. Oboho IK, Tomczyk SM, Al-Asmari AM, Banjar AA, Al-Mugti H, Aloraini MS, et al. 2014 MERS-CoV outbreak in Jeddah-a link to health care facilities. N Engl J Med 2015; 372: 846-854.

6. Liu S, Chan TC, Chu YT, Wu JT, Geng X, Zhao N, et al. Comparative epidemiology of human infections with Middle East respiratory syndrome and severe acute respiratory syndrome coronaviruses among healthcare personnel. PLoS One 2016; 11: e0149988.

7. Kasem S, Qasim I, Al-Doweriej A, Hashim O, Alkarar A, Abu-Obeida A, Saleh M, et al. The prevalence of Middle East respiratory Syndrome coronavirus (MERS-CoV) infection in livestock and temporal relation to locations and seasons. J Infect Public Health 2018; 11: 884-888.

8. World Health Organization. Middle East respiratory syndrome coronavirus (MERS-CoV): summary of current situation, literature update and risk assessment-as of 5 February 2015. [Updated 2015, February 2019]. Available from: http://apps. who.int/iris/bitstream/handle/10665/179184/WHO_MERS_ RA_15.1_eng.pdf?sequence $=2$

9. Monaghan NP. Emerging infections-implications for dental care. Br Dent J 2016; 221: 13-15.

10. Saeed AA, Abedi GR, Alzahrani AG, Salameh I, Abdirizak F, Alhakeem R, et al. Surveillance and Testing for Middle East Respiratory Syndrome Coronavirus, Saudi Arabia, April 20150February 2016. Emerg Infect Dis 2017; 23: 682-685.

11. Baseer MA, Ansari SH, AlShamrani SS, Alakras AR, Mahrous $\mathrm{R}$, Alenazi AM. Awareness of droplet and airborne isolation precautions among dental health professionals during the outbreak of corona virus infection in Riyadh city, Saudi Arabia. J Clin Exp Dent 2016; 8: 379-387.

12. Kharma, MY, Alalwani MS, Amer MF, Tarakji, B, Aws G. Assessment of the awareness level of dental students toward middle east respiratory syndrome-coronavirus. J Int Soc Prev Community Dent 2015; 5: 163-169. 
13. Alqahtani AS. Knowledge and attitude toward Middle East respiratory syndrome coronavirus among heath colleges' students in Najran, Saudi Arabia. Int J Community Med Public Health 2017; 4: 2641-2647.

14. Nour MO, Babilghith AO, Natto HA, Al-Amin FO, Alawneh SM. Knowledge, attitude and practices of healthcare providers towards MERS-CoV infection at Makkah hospitals, KSA. Int Res J Med Med Sci 2015; 3: 103.

15. Abolfotouh MA, AlQarni AA, Al-Ghamdi SM, Salam M, Al-Assiri MH, Balkhy HH. An assessment of the level of concern among hospital-based health-care workers regarding MERS outbreaks in Saudi Arabia. BMC Infect Dis2017; 17: 4.

16. Almutairi MA. Awareness About Middle East Respiratory Syndrome-Corona Virus (Mers-Cov) Among Dental Students in Riyadh, Saudi Arabia. PODJ 2016; 36: 426-429.

17. Zemouri C, de Soet H, Crielaard W, Laheij A. A scoping review on bio-aerosols in healthcare and the dental environment. PloS one 2017; 12: $\mathrm{e} 0178007$.

18. Zingg W, Holmes A, Dettenkofer M, Goetting T, Secci F, Clack L, et al. Hospital organisation, management, and structure for prevention of health-care-associated infection: a systematic review and expert consensus. Lancet Infect Dis 2015; 15: 212-224.

19. Alagaili AN, Briese T, Mishra N, Kapoor V, Sameroff SC, de Wit E, et al. Middle East respiratory syndrome coronavirus infection in dromedary camels in Saudi Arabia. MBio 2014; 5: e00884-14.
20. Memish ZA, Cotten M, Meyer B, Watson SJ, Alsahafi AJ, Al Rabeeah AA, et al. Human infection with MERS coronavirus after exposure to infected camels, Saudi Arabia, 2013. Emerg Infect Dis 2014; 20: 1012-1015.

21. Hemida MG, Alnaeem A, Chu DK, Perera RA, Chan SM, Almathen F, et al. Longitudinal study of Middle East Respiratory Syndrome coronavirus infection in dromedary camel herds in Saudi Arabia, 2014-2015. Emerg Microbes Infect 2017; 6: e56.

22. Anthony SJ, Gilardi K, Menachery VD, Goldstein T, Ssebide B, Mbabazi R, et al. Further evidence for bats as the evolutionary source of Middle East respiratory syndrome coronavirus. MBio 2017; 8: e00373-17.

23. Woo PC, Lau SK, Chen Y, Wong EY, Chan KH, Chen H, et al. Rapid detection of MERS coronavirus-like viruses in bats: potential for tracking MERS coronavirus transmission and animal origin. Emerg Microbes Infect 2018; 7: 18.

24. Mirza MB, Bhagat TV, Inderjit MG, Aljeaidi ZA. Middle East respiratory syndrome and precautions to be taken by dental surgeons. J Health Spec 2016; 4: 105-109.

25. Offner D, Munch LA, Musset AM. Dental Students and Patients with a Communicable Infectious Disease: Any Alteration in the Relationship? Divers Equal Health Care 2017; 14: 249-253. 